ISSN: 2338-4328 (Print), ISSN: 2686-2646 (Online)

\title{
PENGARUH KOMUNIKASI INTERPERSONAL TERHADAP KINERJA PEGAWAI PADA KANTOR BADAN PENANGGULANGAN BENCANA DAERAH KOTA PEMATANGSIANTAR
}

\author{
Marisi Butarbutar ${ }^{1)}$, Efendi $^{2)^{*}}$, Sisca $^{3)}$, Josua Rajagukguk ${ }^{4)}$ \\ ${ }^{1234}$ Program Studi Manajemen, STIE Sultan Agung. Jalan Surabaya No. 19, Kota Pematangsiantar, \\ Sumatera Utara, 21118, Indonesia. \\ *E-mail: ${ }^{1}$ marisibutarbutar84@gmail.com, ${ }^{2}$ efendi.wu@gmail.com, ${ }^{3}$ sizuka_jiang@yahoo.com, \\ josuarajagukguk86@gmail.com
}

\begin{abstract}
Abstrak
Tujuan penelitian ini untuk mengetahui gambaran dan pengaruh komunikasi interpersonal terhadap kinerja pegawai pada Badan Penanggulangan Bencana Daerah Kota Pematangsiantar. Metode penelitian mix method. Hasil penelitian diperoleh bahwa komunikasi interpersonal dan kinerja pegawai sudah baik, serta terdapat pengaruh yang positif dan signifikan antara komunikasi interpersonal terhadap kinerja pegawai.
\end{abstract}

Kata kunci: komunikasi interpesonal dan kinerja.

\section{THE EFFECT OF INTERPERSONAL COMMUNICATION ON EMPLOYEE PERFORMANCE AT THE OFFICE OF THE REGIONAL DISASTER MANAGEMENT AGENCY OF PEMATANGSIANTAR CITY}

\begin{abstract}
The purpose of this study was to determine the description and influence of interpersonal communication on the performance of employees at the Pematangsiantar City Disaster Management Agency. Mix method research method. The results showed that interpersonal communication and employee performance were good, and there was a positive and significant influence between interpersonal communication on employee performance.
\end{abstract}

Key words: interpersonal communication and performance

Article History: $\quad$ Received 12 Mei $2021 \quad$ Revised: 12 Mei $2021 \quad$ Accepted: 22 Mei 2021 


\section{SULTANIST: Jurnal Manajemen dan Keuangan, Vol 9 (1), Juni 2021}

\section{PENDAHULUAN}

Badan Penanggulangan Bencana Daerah Kota Pematangsiantar adalah badan yang melakukan penyelenggaraan penanggulangan bencana di Kota Pematangsiantar. Badan Penanggulangan Bencana Daerah Kota Pematangsiantar menyadari bahwa untuk mencapai visi dan misi diperlukan sumber daya manusia yang memiliki kinerja yang optimal. Kinerja pegawai sangat penting untuk diperhatikan oleh setiap organisasi, karena aspek-aspek yang terdapat untuk tercapainya tujuan organisasi. Representatif dari kinerja diharapkan mampu mendorong produktivitas kerja organisasi dalam mencapai visi dan misi yang telah direncanakan (Lie et al., 2019). Adapun dimensi kinerja pegawai pada Kantor Badan Penanggulangan Bencana Daerah Kota Pematangsiantar teridri dari dimensi penilaian kinerja pegawai yang terdiri dari dua unsur yaitu: Sasaran Kerja Pegawai (SKP) dan Perilaku Kerja (PK) (Indonesia, 2019).

Dalam proses pelaksanaan pengawasan kinerja, sering kali terjadi kendala yang menghambat efektivitas kerja untuk memberikan output yang optimal (Sahir et al., 2020). Fenomena kinerja pegawai yang belum optimal dapat dilihat dari dimensi Sasaran Kerja Pegawai (SKP) dari segi waktu, di mana terdapat pegawai yang keluar kantor pada saat jam kerja untuk urusan lain seperti urusan pribadi. Kemudian untuk dimensi Perilaku kerja (PK) dari sisi kerja sama, terdapat pegawai yang belum optimal bekerja sama misalnya dalam hal pendistribusian logistik.

Salah satu faktor yang diindikasikan mempengaruhi kinerja adalah komunikasi interpersonal. Sejalan dengan penelitian, (Lukmanati, Yulisar and Minartiwi, 2018), bahwa komunikasi interpersonal berpengaruh signifikan terhadap kinerja pegawai. Adapun dimensi komunikasi interpersonal yaitu perbedaan persepsi dan bahasa, pendengaran yang buruk, gangguan emosional, perbedaan budaya dan gangguan fisik. Fenomena komunikasi interpersonal yang belum optimal terjadi pada dimensi gangguan emosional, karena terdapat pegawai yang belum dapat mengentrol emosi dengan baik. Pada dimensi gangguan fisik masih terdapat pegawai yang belum optimal bekerja dengan konsentrasi.

\section{LANDASAN TEORI}

\section{Pengertian Komunikasi Interpersonal}

Dilihat dari asal katanya inter yang berarti antar dan kata person yang berarti orang, maka komunikasi interpersonal baerati berada di antara media komunikasi dan teknologi pada suatu sisi dan komunikasi nonverbal pada sisi lainnya (Luthans, 2006), menyatakan bahwa komunikasi interpersonal merupakan transfer informasi dari satu orang ke orang lain. Demikian dengan (Wood and Setiawan, 2013), menyatakan bahwa komunikasi interpersonal adalah bagian interaksi antar beberapa orang. Definisi ini menunjukkan bahwa komuniasi interpersonal merupaka bagian dari komunikasi lebih personal antar individu.

\section{Faktor Pendukung Komunikasi Interpersonal}

Keberhasilan komunikasi interpersonal dapat didorong oleh faktor berikut ini: keterbukaan, empati, dukungan, rasa positif (Devito, 2011). Demikian juga (Dewi, 2007), beberapa faktor yang membuat komunikasi interpersonal berhasil untuk dihindari: perbedaan persepsi dan bahasa, pendengaran yang buruk, gangguan emosional, perbedaan budaya, dan gangguan fisik. Untuk itu dibutuhkan pemahaman dan pengeloaan faktor tersebut dalam menciptakan komuniasi interpersonal yang efketif.

\section{Jenis Komunikasi Interpersonal}

Pemahaman komunikasi interpersonal dapat dilihat dari jenis-jenisnya, yakni: komunikasi lisan, tertulis, dan non verbal (Robbins and Judge, 2008). Atau menurut assertiveness, aggressiveness, non assertiveness, non verbal communication, dan active listening (Kreitner and Kinicki, 2014). Jenis komunikasi yang manapun dilakukan pastilah tujuannya agar tercapai feedback yang baik dalam komunikasi tersebut. 


\section{SULTANIST: Jurnal Manajemen dan Keuangan, Vol 9 (1), Juni 2021}

\section{Pengertian Kinerja Karyawan}

Menurut (Mangkunegara, 2017), menyatakan bahwa kinerja merupakan hasil kerja secara kaulitas dan kuantitas yang dicapai seseorang pegawai dalam melaksanakan tugasnya sesuai dengan tanggung jawab yang diberikan kepadanya. Demikian dengan (Bangun, 2012), kinerja didefinisikan sebagai hasil pekerjaan yang dicapai seseorang berdasarkan persyaratan-persyaratan (job requirements). Dari kedua teori ini dilihat bahwa kinerja dilihat berdasarkan aktivitas-aktivitas individu yang diakumulasikan menjadi aktivitas organisasi. Lebih lanjut, kinerja merupakan segala sesuatu yang dihasilkan atas dasar aktivitas-aktivitas tertentu melalui tugas dan tanggunjawab yang telah diberikan (Djajasinga et al., 2021). Jika pekerjaan yang dilakukan sesuai dengan standar dan norma yang berlaku di organisasi, maka hal ini akan disebut dengan kinerja yang baik (Indajang et al., 2021).

\section{Dimensi Kinerja Karyawan}

Dimensi kinerja merupakan ukuran kuantitatif atau kualitatif yang menggambarkan tingkat pencapaian sasaran atau tujuan yang diharapkan organisasi. (Bangun, 2012), mengatakan bahwa kinerja memiliki dimensi antara lain: 1) jumlah pekerjaan, dimensi ini menunjukkan jumlah pekerjaan yang dihasilkan individu atau kelompok sebagai persyaratan yang menjadi standar pekerjaan. 2) kualitas pekerjaan, berupa persyaratan pekerjaan yang harus dipenuhi untuk dapat menghasilkan pekerjaan sesuai kualitas yang dituntut suatu pekerjaan tertentu. 3) ketepatan waktu, berupa lamanya suatu pekerjaan untuk diselesaikan dalam kurun waktu tertentu karena setiap pekerjaan memiliki ketergantungan atas pekerjaan lainnya. 4) kehadiran, suatu jenis pekerjaan tertentu menuntut kehadiran karyawan dalam mengerjakannya sesuai waktu yang ditentukan. 5) Kemampuan Bekerja Sama, berupa kemampuan karyawan untuk dapat menyelesaikan suatu jenis pekerjaan dengan kerja sama antar karyawan. Sementara itu, berdasarkan Peraturan Pemerintah Republik Indonesia Nomor 30 tahun 2019 dimensi pengukuran kinerja pegawai terdiri dari (Indonesia, 2019): 1) Sasaran kerja pegawai (SKP) merupakan rencana kerja dan target yang akan dicapai oleh seorang pegawai dan dilakukan berdasarkan kurun waktu tertentu dengan unsur kuantitas, kualitas, waktu, dan biaya; dan 2) Perilaku kerja (PK) merupakan setiap tingkah laku, sikap atau tindakan yang dilakukan oleh seorang pegawai yang seharusnya dilakukan atau tidak dilakukan sesuai dengan ketentuan peraturan perundangundangan yang berlaku, dengan unsur orientasi pelayanan, inisiatif, komitmen, kerja sama, dan kepemimpinan. Dengan demikian pengukuran kinerja dapat dilakukan secara objektif dengan menilai setiap unsur dimensi yang ada.

\section{Pengaruh Komunikasi Interpersonal Terhadap Kinerja Pegawai}

Setiap peawai akan melakukan komunikasi yang baik antar kelompok maupun individu dalam setiap aktivitasnya di organisasi. Salah satu komunikasi yang dilakukan adalah komunikasi interpersonal yang akan mendorong kinerjanya. Sesuai hasil penelitian (Lukmanati, Yulisar and Minartiwi, 2018) dan (Handayani and Suryani, 2019), menunjukkan pengaruh yang signifikan antara komunikasi interpersonal terhadap kinerja pegawai.

\section{METODE}

Penelitian ini dilakukan terhadap 28 PNS Badan Penanggunlangan Bencana Daerah Kota Pematangsiantar. Desain penelitian yang digunakan melalui survei. Dengan data kualitatif dan kuantitatif, dengan sumber data primer dan sekunder. Pengumpulan data lapangan dilakukan dengan observasi, wawancara, dan penyebaran kuesioner. Analisis data dengan mix method dengan analisis kualitatif dan kuantitatif (Sugiyono, 2013).

\section{HASIL DAN PEMBAHASAN}

\section{Hasil Analisis Kualitatif}

Pengelompokan kriteria jawaban rata-rata responden untuk mendeskripsikan jawaban responden secara kualitatif dengan menggunakan tabel berikut:

Tabel 1. Nilai Interval dan Kategori Jawaban Responden

\begin{tabular}{|c|c|c|}
\hline Interval & $\begin{array}{c}\text { Komunikasi } \\
\text { Interpersonal }\end{array}$ & $\begin{array}{c}\text { Kinerja } \\
\text { Pegawai }\end{array}$ \\
\hline $4,21-5,00$ & Sangat Baik & Sangat Baik \\
\hline $3,41-4,20$ & Baik & Baik \\
\hline $2,61-3,40$ & Cukup Baik & Cukup Baik \\
\hline $1,81-2,60$ & Tidak Baik & Tidak Baik \\
\hline $1,00-1,80$ & $\begin{array}{c}\text { Sangat Tidak } \\
\text { Baik }\end{array}$ & $\begin{array}{c}\text { Sangat Tidak } \\
\text { Baik }\end{array}$ \\
\hline
\end{tabular}

Sumber: pengolahan data (2020) 


\section{Gambaran Komunikasi Interpersonal}

Komunikasi interpersonal pegawai Badan

Penanggulangan Bencana Daerah Kota Pematangsiantar dilihat dari beberapa aspek seperti perbedaan persepsi dan bahasa, pendengaran yang buruk, gangguan emosional, perbedaan budaya, gangguan fisik.

Tabel 2. Sebaran Jawaban Responden untuk Komunikasi Interpersonal

\begin{tabular}{|c|l|c|}
\hline No. & \multicolumn{1}{|c|}{ Dimensi Variabel } & $\begin{array}{l}\text { Rata } \\
\text { Skor }\end{array}$ \\
\hline 1 & $\begin{array}{l}\text { Perbedaan Persepsi Dan } \\
\text { Bahasa }\end{array}$ & 3,80 \\
\hline 2 & Pendengaran Yang Buruk, & 3,75 \\
\hline 3 & Gangguan Emosional & 3,51 \\
\hline 4 & Perbedaan Budaya & 3,82 \\
\hline 5 & Gangguan Fisik & 3,54 \\
\hline \multicolumn{2}{|c|}{ Rata-rata } & $\mathbf{3 , 6 8}$ \\
\hline
\end{tabular}

Sumber: pengolahan data

Nilai rata-rata variabel komunikasi interpersonal adalah 3,68 dengan kriteria jawaban baik. Nilai rata-rata tertinggi sebesar 3,80 dengan kriteria baik pada dimensi perbedaan persepsi dan bahasa. Sedangkan nilai rata-rata terendah sebesar 3,51 dengan kriteria baik pada dimensi gangguan emosional.

\section{Gambaran Kinerja Karyawan}

Kinerja pegawai pegawai Badan Penanggulangan Bencana Daerah Kota Pematangsiantar dilihat dari dimensi sasaran kerja pegawai dan perilaku kerja.

Tabel 3. Sebaran Jawaban Responden untuk Kinerja Pegawai

\begin{tabular}{|c|l|c|}
\hline No. & \multicolumn{1}{|c|}{ Dimensi Variabel } & $\begin{array}{c}\text { Rata } \\
\text { Skor }\end{array}$ \\
\hline 1 & Sasasaran Kerja Pegawai & 3,93 \\
\hline 2 & Perilaku Kerja & 3,98 \\
\hline \multicolumn{2}{|c|}{ Rata-rata } & $\mathbf{3 , 9 6}$ \\
\hline
\end{tabular}

Sumber: pengolahan data

Nilai rata-rata variabel kinerja pegawai adalah 3,96 dengan kriteria jawaban baik. Nilai rata-rata tertinggi sebesar 3,98 dengan kriteria baik pada dimensi perilaku kerja. Sedangkan nilai rata-rata terendah sebesar 3,93 dengan kriteria baik pada dimensi sasaran kerja pegawai.

\section{Hasil Analisis Kuantitatif}

\section{Regresi Linier Sederhana}

Untuk menganalisis pengaruh antar variabel digunakan analisis regresi linier sederhana dengan bantuan SPSS berikut ini:

Tabel 4. Hasil Regresi Linier Sederhana

\begin{tabular}{|c|c|r|r|c|}
\hline \multirow{2}{*}{ Model } & \multicolumn{2}{|c|}{$\begin{array}{c}\text { Unstandardized } \\
\text { Coefficients }\end{array}$} & $\begin{array}{c}\text { Standardized } \\
\text { Coefficients }\end{array}$ \\
\cline { 3 - 5 } \multicolumn{2}{|c|}{} & B & Std. Error & Beta \\
\hline \multirow{3}{*}{1} & (Constant) & $\mathbf{4 0 . 1 8 7}$ & 5.981 & \\
\cline { 2 - 5 } & $\begin{array}{c}\text { Komunikasi } \\
\text { Interpersonal }\end{array}$ & $\mathbf{. 5 0 2}$ & .106 & .680 \\
\hline
\end{tabular}

a. Dependent Variable: Kinerja_Pegawai

Sumber: pengolahan data

Berdasarkan tabel 4, ditunjukkan persamaan $\hat{Y}=40,187+0,502 X$, artinya komunikasi interpersonal berpengaruh positif terhadap kinerja pegawai, dimana semakin baik komunikasi interpesonal, maka akan semakin baik kinerja pegawa. Hal ini sejalan dengan penelitian (Lukmanati, Yulisar and Minartiwi, 2018) dan (Handayani and Suryani, 2019) menunjukkan adanya pengaruh komunikasi interpersonal terhadap kinerja pegawai.

\section{Korelasi dan Koefisien Determinasi}

Untuk melihat keeratan hubungan antar variabel dan kontribusi variabel bebas terhadap naik turunnya variabel terikat dapat dilihat dari hasil analisis korelasi dan koefisien determinasi melalui program SPSS berikut:

Tabel 5. Hasil Korelasi dan Determinasi

\begin{tabular}{|c|c|c|c|c|}
\hline $\begin{array}{c}\text { Mod } \\
\text { el }\end{array}$ & $\mathrm{R}$ & $R$ Square & $\begin{array}{c}\text { Adjusted } R \\
\text { Square }\end{array}$ & $\begin{array}{c}\text { Std. Error of the } \\
\text { Estimate }\end{array}$ \\
\hline 1 & $\mathbf{. 6 8 0}$ & $\mathbf{. 4 6 2}$ & .441 & 7.321 \\
\hline
\end{tabular}

a. Predictors: (Constant), Komunikasi Interpersonal b. Dependent Variable: Kinerja_Pegawai

Sumber: pengolahan data

Dari hasil korelasi tabel 5, ditunjukkan nilai $\mathrm{r}=0,680$, maka disimpulkan bahwa hubungan yang kuat dan positif antara komunikasi interpersonal dengan kinerja pegawai. Kemudian diperoleh nilai koefisien determinasi $\mathrm{R}=0,462$ yang berarti baik tidaknya kinerja pegawai sebesar $46,2 \%$ dapat dijelaskan oleh komunikasi interpersonal. Sedangkan sisanya sebesar $63,8 \%$ dapat dijelaskan oleh variable lain yang tidak dibahas dalam penelitian ini. 


\section{SULTANIST: Jurnal Manajemen dan Keuangan, Vol 9 (1), Juni 2021}

\section{Pengujian Hipotesis}

Uji hipotesis yang digunakan dengan uji $t$ dilakukan untuk membuktikan hipotesis yang diajukan sebelumnya. Adapun syarat pengujian dengan melihat nilai signifikansi $\leq$ (lebih kecil atau sama dengan) 0,05, maka hipotesis diterima. Hasil pengujian hipotesi ditunjkkan tabel di bawah:

Tabel 6. Hasil Pengujian Hipotesis

\begin{tabular}{|c|c|c|c|}
\hline \multicolumn{2}{|r|}{ Model } & $\mathrm{t}$ & Sig. \\
\hline & (Constant) & 6,719 &, 000 \\
\hline 1 & $\begin{array}{l}\text { Komunikasi } \\
\text { Interpersonal }\end{array}$ & 4,725 & ,000 \\
\hline
\end{tabular}

a. Dependent Variable: Kinerja_Pegawai

Sumber: pengolahan data

Berdasarkan tabel 6 , ditunjukkan nilai signifikan $0,000<\alpha 0,05$, maka $\mathrm{H}_{0}$ ditolak, artinya komunikasi interpersonal berpengaruh positif dan signifikan terhadap kinerja pegawai. Hasil pengujian ini sejalan dengan penelitian (Lukmanati, Yulisar and Minartiwi, 2018) dan (Handayani and Suryani, 2019) yang menunjukkan pengaruh yang positif dan signifikan antara komunikasi interpersonal terhadap kinerja pegawai.

\section{Pembahasan}

\section{Komunikasi Interpersonal}

Komunikasi interpersonal pegawai Badan Penanggulangan Bencana Daerah Kota Pematangsiantar dapat dikatakan belum optimal seluruhnya. Hal ini dapat dilihat dari tiap dimensi komunikasi interpersonal dengan nilai masih di bawah nilai rata-rata keseluruhan 3,68, secara khusus pada dimensi gangguan emosional (nilai rata-rata 3,51) dan dimensi gangguan fisik (nilai rara-rata 3,54). Untuk itu dibutuhkan upaya dalam mengoptimalkan komunikasi interpersonal yang masih di bawah rata-rata tersebut. Untuk dimensi gangguan emosional dalam hal pengelolaan emosi pegawai agar pimpinan memotivasi pegawai dan sesama pegawai memberikan dukungan terhadap rekan kerjanya dengan meningkatkan keakraban dan kerjasama yang baik antar sesama pegawai. Demikian halnya dengan dimensi gangguan fisik dari lingkungan kerja agar pegawai lebih memperhatikan kerapian dan kebersihan ruang kantor agar pegawai dalam bekerja dapat merasakan kenyamanan dan lebih meningkatkan kualitas kerja pegawai, demikian juga pimpinan dapat memberikan teguran pada pegawai dengan ruangan kerja yang tidak tertata.

\section{Kinerja Karyawan}

Kinerja pegawai Badan Penanggulangan Bencana Daerah Kota Pematangsiantar dapat dikatakan belum optimal seluruhnya. Hal ini dapat dilihat dari tiap dimensi kinerja pegawai dengan nilai masih di bawah nilai rata-rata keseluruhan 3,96, khususnya sasaran kerja pegawai (nilai rata-rata 3,93). Untuk itu dibutuhkan upaya dalam mengoptimalkan kinerja yang masih di bawah rata-rata tersebut. Untuk dimensi sasaran kerja pegawai yang belum optimal terkait dengan efisiensi waktu kerja, dapat dioptimalkan dengan kesadaran pegawai menggunakan waktu dengan baik dan tidak melakukan sesuatu diluar pekerjaan yang ada di kantor.

\section{SIMPULAN DAN SARAN}

\section{Simpulan}

Dari hasil analisis dan pembahasan ditemukan bahwa komunikasi interpersonal dan kinerja pegawai sudah baik, serta terdapat pengaruh positif dan signifikan antara komunikasi interpersonal terhadap kinerja pegawai.

\section{Saran}

Upaya meningkatkan komunikasi interpersonal dengan dimensi dibawah nilai ratarata dukungan sesame pegawai melalui keakraban dan kerjasama, serta memperhatikan ruangan kerja yang tertata sehingga tidak menggangu komunikasi. Sedangkan untuk mengoptimalkan kinerja dengan mendorong kesadaran pegawai untuk menggunakan waktu dengan efisien.

\section{DAFTAR PUSTAKA}

Bangun, W. (2012) Manajemen Sumber Daya Manusia. Jakarta: Erlangga.

Devito, J. A. (2011) Komunikasi Antar Manusia. Edited by L. et. al. Saputra. Tangerang: Karisma Publishing Group.

Dewi, S. (2007) Komunikasi Bisnis. Edited by R. W. Rosari. Yogyakarta: CV. ANDI OFFSET.

Djajasinga, N. D., Sulastri, L., Sudirman, A., Sari, A. L., \& Rihardi, L. (2021). Practices in Human Resources and 


\section{SULTANIST: Jurnal Manajemen dan Keuangan, Vol 9 (1), Juni 2021}

Employee Turnover in the Hospitality Industry. Proceedings of the 2nd Annual Conference on Blended Learning, Educational Technology and Innovation (ACBLETI 2020) Practices, 560(Acbleti 2020), 113-117.

Handayani, L. and Suryani, N. (2019) 'Pengaruh Kinerja Pegawai, Komunikasi Interpersonal dan Lingkungan Kerja Fisik Terhadap Kepuasan Masyarakat Melalui Kualitas Pelayanan', Economics Education Analysis Journal, 8(2), pp. 743-757. doi: https://doi.org/10.15294/eeaj.v8i2.31504.

Indajang, K., Halim, F., \& Sudirman, A. (2021). The Effectiveness of Teacher Performance in Terms of the Aspects of Principal Leadership , Organizational Culture, and Teacher Competence. Proceedings of the 2nd Annual Conference on Blended Learning, Educational Technology and Innovation (ACBLETI 2020), 560(Acbleti 2020), 402-408.

Indonesia, P. R. (2019) Penilaian Prestasi Kerja Pegawai Negeri Sipil. Indonesia.

Kreitner, R. and Kinicki, A. (2014) Perilaku Organisasi (Organizational Behavior). 9th edn. Jakarta: Salemba Empat.

Lie, D., Sherly, S., Dharma, E., \& Sudirman, A. (2019). The Impact of Work Discipline and Work Ethic on the Teacher Performance of Sultan Agung Pematangsiantar Private Middle School
Teachers T.A. 2018/2019. International Journal of Business Studies, 3(3), 125135. https://doi.org/10.32924/ijbs.v3i3.83

Lukmanati, Yulisar, B. and Minartiwi, Y. (2018) 'Pengaruh Komunikasi Interpersonal terhadap Kinerja Pegawai Pada SMA Pomosda Tanjunganom Nganjuk', CyberTechn, 3(1), pp. 65-75. Available at: https://ojs.stt-

pomosda.ac.id/index.php/cybertechn/artic le/view/48.

Luthans (2006) Perilaku Organisasi (Organizational Behavior). 10th edn. Yogyakarta: Andi.

Mangkunegara, A. A. A. P. (2017) Manajemen Sumber Daya Manusia Perusahaan. Bandung: PT. Remaja Rosda Karya.

Robbins, P. S. and Judge, T. A. (2008) Perilaku Organisasi (organizational behavior. 12th edn. Jakarta: Salemba Empat.

Sahir, S. H., Fadhli, M., Sudirman, A., Hasibuan, A., Chamidah, D., Salmiah, Sherly, Revida, E., Simarmata, J., \& Purba, S. (2020). Keterampilan Manajerial Efektif. Yayasan Kita Menulis.

Sugiyono (2013) Metode Penelitian Kuantitatif Kualitatif dan $R \& D$. Bandung: Alfabeta.

Wood, J. and Setiawan, R. D. (2013) Komunikasi interpersonal: Interaksi Keseharian. 6th edn. Jakarta: Salemba Humanika. 